\title{
Manfaat Vessel Traffic System (VTS) di Alur Pelayaran Tanjung Emas Semarang
}

\author{
Karolus G Sengadji ${ }^{\mathrm{a}}$, Mustholiq ${ }^{\mathrm{b}}$, Dimas Satria Hemarnaswa ${ }^{\mathrm{c}}$, Ariska Hendra \\ Jaya $^{\mathbf{d}^{*}}$
}

\author{
a,b,c,d Politeknik Ilmu Pelayaran Semarang

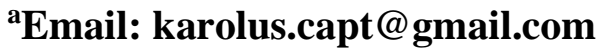 \\ bEmail: mustholiq.pip.smg.65@gmail.com \\ 'Email: dimashmw@gmail.com \\ d*Email: ariskahendra49@gmail.com
}

\begin{abstract}
ABSTRAK
Penelitian ini bertujuan untuk mengetahui apakah Vessel Traffic System (VTS) di Tanjung Emas sudah cukup memberikan manfaat kepada para pengguna fasilitas pelabuhan. Penelitian ini dilakukan untuk mengetahui apakah implementasi VTS sebagai bentuk kemajuan teknologi (IPTEK) dalam dunia maritim telah dinikmati secara penuh oleh para pengguna jasa pelayaran. Dalam mendapatkan data dan pengisian kuesioner di penelitian ini menggunakan sampel dari kantor pelayaran dan Anak Buah Kapal (ABK) sebanyak 60 orang. Metode penelitian yang digunakan adalah deskriptif kualitatif dan teknik pengambilan sampel dalam penelitian ini adalah nonprobability sampling dengan metode purposive sampling. Berdasarkan hasil penelitian dapat disimpulkan bahwa pengguna jasa VTS merasa puas dengan pelayanan yang diberikan kepada kapal. Sistem informasi yang dimiliki oleh VTS Tanjung Emas sudah cukup efektif dalam memberikan informasi terkait pelayaran di Tanjung Emas. VTS memberi peran ekonomi yang cukup besar kepada negara melalui pembayaran PNBP.
\end{abstract}

Kata Kunci: sistem lalu lintas kapal, pelabuhan tanjung emas

\section{ABSTRACT}

This study aims to determine whether the Vessel Traffic System (VTS) in Tanjung Emas is sufficient to provide benefits to users of port facilities. This research was conducted to determine whether the implementation of VTS as a form of technological advancement (science and technology) in the maritime world has been fully enjoyed by shipping service users. In obtaining data and filling out the questionnaire in this study using a sample of 60 people from the shipping office and ship crew $(A B K)$. The research method is descriptive qualitative method and the sampling technique in this study is non-probability sampling with purposive sampling method. Based on the research results it can be concluded that VTS service users are satisfied with the services provided to vessels. The information system owned by VTS Tanjung Emas is quite effective in providing information related to shipping in Tanjung Emas. VTS gives a sizable economic role to the state through PNBP payments.

Keywords: vessel traffic system, tanjung emas port

\section{PENDAHULUAN}

Menurut BPS (2017) negara

Indonesia adalah negara kepulauan yang terdiri 17.509 pulau dan sangat membutuhkan kapal sebagai moda transportasi untuk mengangkut barang, orang, maupun hewan dari suatu pulau ke pulau lain demi terwujudnya pemerataan pembangunan dan peningkatan kesejahteraan dalam mewujudkan sila kelima dari Pancasila yaitu keadilan sosial bagi seluruh rakyat Indonesia. Distribusi barang berjalan lancar, aman, selamat, dan tepat waktu sampai ke tempat tujuan jika didukung oleh alat angkut/kapal yang laik laut, awak kapal yang memenuhi persyaratan baik jumlah maupun kompetensinya 
serta daerah pelayaran yang aman. Apalagi sekitar $80 \%$ perdagangan global dilewatkan laut sehingga sistem transportasi laut adalah hal yang fundamental untuk ekonomi dunia (Xu, Pan, Muscoloni, Xia, \& Cannistraci, 2020).

Wilayah laut lebih luas daripada wilayah darat dengan posisi yang strategis diapit oleh dua benua yakni benua Australia dan benua Eropa serta dua samudra yaitu samudra Hindia dan samudra Pasifik, maka wilayah perairan indonesia memiliki nilai strategis sebagai jalur komunikasi dan perdagangan, Sea Lanes of Communication (SLOC) dan Sea Lanes of Trade (SLOT) bagi pelayaran internasional dari Samudra Hindia dan Selat Malaka ke Samudra Pasifik dan Laut Tiongkok Selatan. Sehingga, selama abad ke duapuluh bisa dilihat Indonesia mempertahankan secara tradisional mengikuti 'wawasan nusantara' yang melihat ke dalam yang berfokus pada mempertahankan kendali atas pulau-pulau dan perairannya yang jauh (Scott, 2019).

Dalam perkembangan lingkungan global, regional saat ini yang begitu cepat memengaruhi aspek kehidupan nasional, dimana percepatan ini mempunyai kecenderungan menimbulkan pola-pola hubungan baru antar manusia dan kelompok manusia yang kemudian dikenal sebagai era globalisasi. Sekarang ini globalisasi bukanlah sesuatu yang baru (Michie, 2017) yang merupakan gabungan berbagai perkembangan dan transformasi yang kompleks baik secara ekonomi, teknologi, budaya, dan sosial (Martin, Tyler, Storper, Evenhuis, \& Glasmeier, 2018) sehingga memengaruhi cara masyarakat hidup dan juga memperoleh mata pencaharian (Shrestha, et al., 2020). Era globalisasi merupakan suatu era serba terbuka yang telah melahirkan model baru peradaban dunia yang dalam praktiknya didasari pada kemajuan ilmu pengetahuan dan teknologi (IPTEK), khususnya teknologi informasi, komunikasi, dan transportasi. Kondisi ini cenderung meningkatkan keberhasilan ekonomi negara-negara berkembang dan ekonomi yang dalam transisi akan di kembangkan (Mohaghegh, 2016). Bangsa Indonesia harus mampu memanfaatkan sumber daya yang di miliki agar dapat sejajar dengan bangsabangsa lain yang lebih maju dan modern. Wilayah maritim Indonesia apabila dikelola dengan baik dan benar akan mendatangkan kesejahteraan dan kemakmuran bagi seluruh masyarakat Indonesia. Laut sendiri adalah pusat kesejahteraan manusia yang mengatur iklim dan menyediakan makanan, energi, mineral, dan sumber daya genetik serta layanan budaya dan rekreasi (Claudet, Loiseau, Sstres, \& Zupan, 2020). Selain itu, ekosistem laut memberikan beragam nilai dan memenuhi kebutuhan manusia (Thushari \& Senevirathma, 2020) yang bisa berharga ratusan miliar dolar (Viglione, 2021) yang berarti laut sangatlah penting.

Dalam kaitan dengan jasa kelautan, fungsi laut secara konvensional adalah sebagai media transportasi yang mengutamakan keamanan, keselamatan, kenyamanan, dan ketepatan waktu tiba. Bangsabangsa memiliki kepentingan bersama dalam memfasilitasi perdagangan maritim, mempertahankan transportasi laut, dan melindungi dari teroris serta kriminal (Turedi \& Ozer-Caylan, 2021). Tertibnya keamanan, keselamatan, dan kelancaran transportasi laut sangat tergantung dari kepedulian (awareness) para pemilik kapal dan perusahan pelayaran dalam menerapkan sistem keselamatan yang efektif dan implementatif di lapangan. Menurut konsep dasar keselamatan pelayaran kapal yang hendak berlayar harus dalam keadaan laik laut (Seaworthiness), artinya kapal layak menghadapi berbagai resiko dan kejadian secara wajar dalam pelayaran, layak menerima muatan agar kapal tiba 
dengan aman dan selamat di pelabuhan tujuan.

Hal-hal yang menjadi faktor penunjang keselamatan dalam berlayar antara lain sarana bantu navigasi, peralatan telekomunikasi, serta alur pelayaran. Segala alat dan sistem di luar kapal yang dirancang dan digunakan sebagai penjaga keselamatan serta efisiensi dalam navigasi kapal atau lalu lintas kapal disebut sebagai sarana bantu navigasi. Telekomunikasi pelayaran merupakan alat telekomunikasi yang meliputi aktivitas pengiriman atau penerimaan segala jenis informasi gambar, suara, tanda, atau yang lainnya melalui sistem elektromagnetik. Alur pelayaran merupakan perairan yang di nilai aman jika dilihat dari segi lebar, kedalaman, dan kebebashambatan.

$$
\text { Tiga faktor penunjang }
$$

keselamatan pelayaran tersebut di atas merupakan tanggung jawab pemerintah. Dalam hal ini pemerintah yang di maksud adalah Kementerian Perhubungan melalui Direktorat Jenderal Perhubungan Laut khususnya Direktorat Kenavigasian. Dalam kebijakan pemerintah untuk meningkatkan keamanan dan keselamatan pelayaran di wilayah Jawa Tengah khususnya alur pelayaran Tanjung Emas pada tahun 2013 telah dipasang peralatan VTS di kantor Distrik Navigasi Kelas II Semarang untuk memantau lalu lintas kapal yang keluar/masuk ataupun berlabuh jangkar dan melakukan kegiatan di daerah lingkungan kerja pelabuhan (DLKr) atau di daerah lingkungan kepentingan pelabuhan (DLKP). Beberapa peran VTS yakni: (i) mengetahui/mengikuti pergerakan kapal, (ii) memberi informasi navigasi/cuaca, (iii) kondisi sarana bantu navigasi pelayaran (SBNP), (iv) kepadatan lalu lintas di daerah pelayaran. Peneliti tertarik melakukan penelitian ini karena ingin mengetahui manfaat peralatan VTS yang canggih dan modern ini terhadap keselamatan pelayaran serta manfaat yang diperoleh operator atau perusahaan pelayaran yang telah membayar
Penerimaan Negara Bukan Pajak (PNBP) setiap kali kapalnya masuk/keluar ke dan dari pelabuhan Tanjung Emas Semarang.

Tujuan penelitian ini adalah untuk mengetahui apakah peralatan VTS yang sudah terpasang selama 5 tahun ini telah dinikmati manfaatnya oleh pengguna jasa transportasi laut/ angkutan di perairan dalam hal keamanan dan keselamatan pelayaran.

Penelitian ini dilakukan dengan harapan untuk dapat memberi kontribusi dan manfaat dengan memberi masukan atau menambah kajian pemanfaatan VTS dalam meningkatkan keselamatan pelayaran khusus wilayah alur masuk/keluar kapal di suatu pelabuhan. Secara praktis, hasil penelitian diharapkan dapat dimanfaatkan oleh pengguna jasa di pelabuhan Tanjung Emas untuk memonitor posisi kapalnya yang akan berkegiatan di daerah lingkungan kerja pelabuhan maupun lingkungan kepentingan pelabuhan, agar dapat mengantisipasi gangguan keamanan dan berupaya meningkatkan keselamatan pelayaran.

Vessel Traffic System adalah sistem monitoring lalu lintas pelayaran yang diterapkan oleh pelabuhan atau suatu manajemen armada perkapalan. Teori Early warning dapat menjabarkan manfaat VTS karena peralatan utama dari VTS terdiri dari Radar, $C C T V$, Radio VHF, dan Automatic Indentivication System (AIS) sehingga dapat memberi peringatan dini dari meteorologi/cuaca, pergerakan kapal maka dapat menghindari kecelakaan kapal atau meningkatkan keselamatan pelayaran.

Melengkapi kajian teori dapat kami paparkan beberapa kajian pustaka sebagai berikut, Undang-Undang Nomor 17 Tahun 2008 tentang Pelayaran pasal 1(32) mendefinisikan keselamatan dan keamanan pelayaran adalah suatu keadaan terpenuhinya persyaratan keselamatan dan keamanan yang menyangkut angkutan di perairan, kepelabuhanan, dan lingkungan maritim. Salah satu upaya memenuhi persyaratan keselamatan pelayaran/angkutan di 
perairan, dipasanglah VTS di pelabuhan Tanjung Emas Semarang agar daerah lingkungan kerja dan lingkungan kepentingan pelabuhan Semarang aman dan nyaman bagi pengguna jasa. Pelabuhan adalah tempat yang terdiri atas daratan dan/atau perairan dengan batasbatas tertentu sebagai tempat kegiatan pemerintahan dan kegiatan pengusahaan yang di pergunakan sebagai tempat kapal bersandar, naik turun penumpang, dan/ atau bongkar muat barang, berupa terminal dan tempat berlabuh kapal yang dilengkapi dengan fasilitas keselamatan dan keamanan pelayaran dan kegiatan penunjang pelabuhan serta sebagai tempat pemindahan intra dan antarmoda transportasi.

Alur pelayaran adalah perairan yang dari segi kedalaman, lebar, dan bebas hambatan pelayaran lainnya dianggap aman dan selamat untuk di layari. Sarana Bantu Navigasi Pelayaran (SBNP) adalah peralatan atau sistem yang berada di luar kapal yang didesain dan di operasikan untuk meningkatkan keselamatan dan efisiensi bernavigasi kapal dan/atau lalu lintas kapal. Telekomunikasi pelayaran adalah telekomunikasi khusus untuk keperluan dinas pelayaran yang merupakan setiap pemancaran, pengiriman, atau penerimaan setiap jenis tanda, gambar, suara dan informasi dalam bentuk apapun melalui sistem kawat, optik, radio, atau sistem elektromagnetik lainnya dalam dinas bergerak pelayaran yang merupakan bagian dari keselamatan pelayaran.

Dinas Bergerak Pelayaran adalah suatu dinas bergerak antara stasiun pantai dengan stasiun-stasiun kapal atau antar stasiun-stasiun kapal atau antar stasiun komunikasi yang ada di atas kapal, sedangkan stasiun-stasiun sekoci penolong dan stasiun-stasiun rambu radio petunjuk posisi darurat dapat juga mengambil bagian dalam tugas ini.

Vessel Traffic System (VTS) adalah pelayanan lalu lintas kapal di wilayah yang ditetapkan yang saling terintegrasi dan dilaksanakan oleh pihak yang berwenang (Menteri Perhubungan) serta di rancang untuk meningkatkan keselamatan kapal, efisiensi bernavigasi dan menjaga lingkungan, yang memiliki kemampuan untuk berinteraksi dan menanggapi situasi perkembangan lalu lintas kapal di wilayah VTS dengan menggunakan sarana perangkat radio dan elektronika pelayaran (PM 26 Tahun 2011 Pasal 1 ayat 8 tentang Telkompel).

Dasar hukum yang mengatur Vessel Traffic System (VTS) adalah sebagai berikut. Untuk hukum internasional:

1. International Convention for Safety of Life at Sea (SOLAS) 1974, dan amandemennya;

2. Radio Regulation, ITU;

3. IMO Resolution A.851 berkaitan dengan Ship Reporting System (SRS);

4. IMO Resolution A.851 (20) berkaitan dengan Vessel Traffic Services (VTS);

5. Resolution MSC.202 (81) berkaitan dengan Long Range Identification and Tracking of Ship (LRIT);

6. IALA VTS Manual 2008.

Untuk hukum nasional:

1. UU Nomor 36 Tahun 1999 tentang Telekomunikasi;

2. UU Nomor 17 Tahun 2008 tentang Pelayaran;

3. Peraturan Pemerintah PP No. 64 Tahun 2015 tentang Kepelabuhanan;

4. Peraturan Pemerintah Peraturan Pemerintah No. 31 tahun 2021 tentang Penyelenggaraan Bidang Pelayaran;

5. Peraturan Pemerintah Nomor 15 Tahun 2016 tentang Jenis dan Tarif Atas Jenis Penerimaan Negara Bukan Pajak Yang Berlaku Pada Kementerian Perhubungan;

6. Peraturan Pemerintah Nomor 26 Tahun 2011 tentang Telkompel;

7. Peraturan Pemerintah Nomor 25 Tahun 2011 tentang SBNP;

8. Peraturan Pemerintah Nomor 26 Tahun 2011 tentang Petunjuk Pelaksanaan Jenis dan Tarif Atas 
Jenis Penerimaan Negara Bukan Pajak;

9. Permenhub Nomor PM 129 tahun 2016 tentang Alur Pelayaran di Laut;

10. Peraturan Menteri Perhubungan Nomor 58 Tahun 2019 Tentang Perubahan Atas Peraturan Menteri Perhubungan Nomor PM 07 Tahun 2019 tentang Perubahan Atas Peraturan Menteri Perhubungan Nomor PM 07 Tahun 2019 Tentang Pemasangan dan Pengaktifan Sistem Identifikasi Otomatis bagi Kapal yang Berlayar di Wilayah Perairan Indonesia;

11. Peraturan Dirjen Perhubungan Laut KN 404- 2-11-DJPL-15 tentang Tata Cara Penerimaan, Penyetoran, Penggunaan, dan Pelaporan Penerimaan Negara Bukan Pajak Yang Berlaku Pada Direktorat Jenderal Perhubungan Laut;

12. Surat Edaran Nomor UM. 003/15/3/DJPL-2018 tentang Pemberlakuan Penerapan PNBP Jasa Kenavigasian Pelayanan Vessel Traffic Services (VTS), Pelayanan Jasa Telegram/Telpon Radio/Radio Telex dan Penggunaan SBNP di Lingkungan Direktorat Jenderal Perhubungan Laut.

Keberadaan VTS sesuai ketentuan PM Nomor 26 Tahun 2011 pasal 2 tentang Telekomunikasi Pelayaran, bahwa Sarana

Telekomunikasi Pelayaran terdiri atas:

1. Stasiun Radio Pantai (SROP);

2. Vessel Traffic Services (VTS).

Tugas pokok dan fungsi VTS

Fungsi VTS berdasarkan ketentuan PM Nomor 26 Tahun 2011 pasal 5 tentang Telkomunikasi Pelayaran yaitu:

1. Memonitor lalu lintas pelayaran dan alur lalu lintas pelayaran;

2. Meningkatkan keamanan lalu lintas pelayaran;

3. Meningkatkan efisiensi bernavigasi;

4. Perlindungan lingkungan;

5. Pengamatan, pendeteksian dan penjejakan kapal di wilayah cakupan VTS;
6. Pengaturan informasi umum;

7. Pengaturan informasi khusus;

8. Membantu kapal-kapal yang memerlukan bantuan khusus.

Standar peralatan VTS sesuai ketentuan pasal 17 ayat 3 dan IALA V128 sebagai berikut:

1. VTS Radar Console;

2. Closed Circuit TV Cameras (CCTV);

3. Automatic Identification System (AIS);

4. VHF Radio;

5. Electronic Navigation Chart (NEC);

6. VTS Data System;

7. Perangkat penerima data hidrologi. Perangkat penunjang untuk stasiun VTS (PM No. 26 Tahun 2011 Pasal 18 ayat 4 sebagai berikut:

1. Pendingin Ruangan (AC);

2. Kelengkapan administrasi;

3. Kendaraan;

4. Mebelair;

5. Perangkat Komputer.

Pemeliharaan dan perbaikan VTS Pemeliharaan dan perbaikan VTS sesuai ketentuan PM 26 Tahun 2011 pasal 31 terdiri atas:

1. Pembersihan debu;

2. Pengecekan catu daya;

3. Kalibrasi peralatan;

4. Menjaga suhu ruangan tetap stabil;

5. Pengecekan panel-panel;

6. Updating perangkat lunak;

7. Penggantian spare unit dan spare part;

8. Penggantian peralatan.

\section{METODE PENELITIAN}

Penelitian ini menggunakan metode kualitatif. Pendekatan yang digunakan adalah deskrkiptif dimana peneliti menjelaskan dan memberikan gambaran mengenai objek dan fakta yang terjadi di lapangan.

Dalam penelitian kualitatif, temuan atau hasil penelitian tidak didapatkan melalui teknik-teknik analisis statistik atau hitungan lainnya (Sugiyono, 2014). Hasil dari sebuah penelitian kualitatif lebih kepada kalimat atau lisan yang bersifat deskriptif dari perilaku objek yang diamati. Metode kualitatif 
digunakan dalam pembahasan untuk memaparkan semua hasil telah didapat mengenai objek yang di teliti.

Penelitian ini dilakukan di Kantor Distrik Navigasi Klas II Semarang, Kantor Kesyahbandaran dan Otoritas Pelabuhan (KSOP) Klas I Tanjung Emas, Kantor PT. Pelindo III cabang Tanjung Emas, Kantor PT. Pelni Semarang, Kantor Dharma Lautan Utama Semarang, dan Kantor Indonesia Ship Owners Asosiation (INSA) Semarang. Penelitian dilakukan selama 9 (sembilan) bulan yaitu mulai Januari 2020 sampai dengan September 2020, di awali dengan survei, usulan penelitian, pelaksanaan penelitian dan laporan hasil penelitian.

Penelitian ini mengunakan metode deskriptif dimana akan di gambarkan atau menjelaskan objek yang diteliti serta akan dibandingkan persamaan dan perbedaan serta keuntungan dan kerugiannya. Obeservasi merupakan kegiatan pengumpulan data melalui pengamatan langsung terhadap keadaan atau situasi dari objek penelitian.

Metode ini peneliti lakukan langsung di ruangan operasi VTS melihat peralatan pokok, mengetahui pelaksanan komunikasi dari operator dan nakhoda kapal atau sebaliknya serta prosedur pelayanan kepada pengguna jasa baik di kantor Distrik Navigasi Klas II Semarang, maupun di kantor Kesyahabandaran dan Otoritas Pelabuhan kelas I Tanjung Emas Semarang.

Wawancara atau interviu adalah kegiatan percakapan yang memiliki sebuah tujuan khusus antara pewawancara dan objek yang di wawancarai. Peneliti akan langsung melakukan wawancara dengan operator VTS, Kasie Operasi Distrik Navigasi Klas II Semarang, Manajer Pemanduan PT. Pelindo Tanjung Emas, Kepala Cabang PT Pelni Semarang, Kepala Cabang PT. Dharma Lautan Utama Semarang, Kabid KPLP KSOP Tanjung Emas dan Ketua Insa.

Dokumentasi adalah usaha untuk mendapatkan data yang berupa tulisan maupun gambar yang berhubungan dengan tujuan penelitian. Data-data yang digunakan pada penelitian ini berbentuk surat, laporan, peraturan, ataupun catatan harian yang berhubungan dengan objek penelitian.

Pada penelitian kualitatif, keabsahan data menjadi perhatian penting untuk menjamin keaslian dan validitas data yang telah dikumpulkan. Uji keabsahan data pada penelitian ini menggunakan teknik triangulasi. Menurut Moleong (2012), triangulasi adalah teknik validasi data yang menggunakan sesuatu selain data untuk keperluan verifikasi atau untuk membandingkannya dengan data. Dalam teknik triangulasi, peneliti membandingkan hasil wawancara masing-masing sumber atau informan penelitian sebagai pembanding atau memverifikasi kebenaran data yang diterima untuk memperoleh hasil yang valid (Moleong, 2012).

Analisis data adalah kegiatan merinci secara formal untuk menemukan tema dan merumuskan hipotesis atau ide sesuai dengan data yang didapatkan (Moleong, 2004). Teknik analisis data peneliti menggunakan metode deskriptif untuk menguraikan atau menjabarkan data-data yang diperoleh melalui wawancara, dokumentasi maupun data yang diperoleh dari analisis secara kualitatif serta dijelaskan dalam bentuk deskriptif. Dalam menganalisis data dapat dilakukan setelah semua data terkumpul atau secara bersamaan dilakukan sambil mkengumpulkan data. Menurut H.B. Sutopo (2002: 91) dalam teknik menganalisa data peneliti harus memahami 3 (tiga) komponen utama yaitu, (i) reduksi data, (ii) penyajian data, (iii) verifikasi dan penarikan kesimpulan, dimana ketiga komponen ini saling berkaitan untuk menentukan hasil akhir yang valid.

Reduksi data adalah kegiatan membuat rangkuman, memilih dan fokus pada bagian-bagian yang dianggap penting, mencari tema dan pola, dan membuang bagian yang tidak perlu. Semakin banyak data yang didapat atau terkumpul semakin banyak pula waktu 
dan tenaga untuk melakukan analisa maka peneliti perlu melakukan reduksi data-data yang valid dan mencapai manfaat penelitian dan mengurangi datadata yang kurang mendukung serta mencari data tambahan yang mendukung tujuan penelitian baik dari sumber data primer maupun sekunder. Proses reduksi data berlangsung terusmenerus sepanjang pelaksanaan penelitian, dengan maksud memperpendek proses, mempertegas, membuat lebih fokus, dengan membuang hal-hal yang tidak penting.

\section{HASIL DAN PEMBAHASAN}

Dengan adanya pergerakan kapal yang menggunakan jasa VTS Tanjung Emas juga memberikan sumbangsih cukup besar terhadap perekonomian negara sebesar Rp. 883.742.930 dalam bentuk Penerimaan Negara Bukan Pajak (PNBP). VTS merupakan sarana vital yang mempunyai peran sangat penting dalam kegiatan lalu lintas laut bagi kapalkapal. Dengan adanya VTS maka bahaya navigasi yang ada di laut dapat terdeteksi dan dengan cepat dapat diinformasikan secara jelas ke kapalkapal yang ada.

Setiap kapal yang melintas masuk ke daerah VTS Tanjung Emas wajib memanggil VTS melalui radio VHF Ch. 16, lalu kemudian VTS akan menjawab untuk memastikan titik koordinat kapal tersebut sesuai dengan koordinat yang ada dimonitor VTS. Tidak hanya itu, informasi terkait jenis muatan kapal, jumlah kru kapal, pelabuhan terakhir yang disinggahi kapal dan bahkan dalam beberapa kondisi VTS juga akan bertanya mengenai kewarganegaraan nahkoda dan para kru kapal. Begitu juga saat kapal yang akan melintas keluar daerah VTS Tanjung Emas, wajib memanggil melalui radio VHF dan melaporkan koordinat kapal serta pelabuhan tujuan berikutnya.

Jika kapal yang memanggil VTS tidak mendapatkan jawaban maka alternatif lain adalah dengan memanggil melalui kapal pandu terdekat, pandu yang sedang ada di atas kapal tersebut akan menghubungi kapal pandu dan status yang ada akan di sampaikan melalui kapal pandu tersebut ke VTS. Dalam penelitian ini didapatkan data-data terkait lalu lintas kapal yang ada di daerah Tanjung Emas Semarang, dan dilakukan survei melalui kuesioner secara tersebar kepada para pengguna jasa VTS yang ada di Tanjung Emas. Dengan sistem kuesioner yang dibagikan secara daring, para pengguna jasa akan mengisi kuesioner tersebut lalu mengirimkan kembali dalam bentuk softcopy atau bisa juga dengan hardcopy.

Perangkat VTS Semarang telah ada sejak 2006 dan pada tahun 2016 telah diadakan peningkatan perangkat melalui DIPA Tahun 2016. Secara kebutuhan standar minimal perangkat VTS yang diatur pada pasal 17 ayat 3 . Peraturan Menteri Perhubungan No. 26 Tahun 2011 tentang Telkompel dan IALA V-128 Operational and Technical Performance Requirements for VTS Equipment sudah memenuhi ketentuan tersebut, dalam rangka meningkatkan monitoring lalu lintas kapal maka perlu penambahan perangkat:

1. Perangkat penerima data hidrologi yang berkaitan memberikan informasi cuaca, kecepatan angin, kecepatan arus dan terutama peringatan dini gelombang tinggi.

2. Penambahan radar sebagai sarana pendukung pendeteksian kapal-kapal di sekitar alur pelayaran di Pelabuhan Tanjung Emas.

Dalam rangka melakukan optimalisasi penggunaan VTS, maka secara berkala diadakan perawatan harian, mingguan, dan bulanan sebagai berikut:

a. Setiap hari membersihkan debu yang ada di monitor dan yang ada di ruang server; Setiap minggu diadakan perawatan genset, server dan remote site yang ada di 
KSOP;

b. Setiap bulan perawatan server dan pengecekan tower radar;

c. Setiap hari mengadakan pengecekan dan pembersihan perangkat yang ada di stasiun VTS.

Sesuai dengan SOP yang ada di kantor Distrik Navigasi Tanjung Emas dan pelaksanaan PNBP (Penerimaan Negara Bukan Pajak) yang dimulai sejak bulan April 2016, maka operasional VTS Semarang menjadi lebih optimal sesuai dengan prosedur yang ada sehingga memperkuat kinerja VTS Semarang. Dengan adanya SOP VTS yang sudah resmi dan diperkuat dengan PNBP maka dapat memberikan kontribusi peningkatan ketertiban, keamanan, dan keselamatan di alur pelayaran dan lebih mudah pengaturan terutama dalam hal manajemen lalu lintas kapal di alur pelabuhan Tanjung Emas yang meliputi:

1. Pelaporan apabila kapal keluar masuk di pelabuhan;

2. Posisi kapal berlabuh jangkar;

3. Kecepatan kapal masuk dan keluar alur;

4. Tempat olah gerak kapal;

5. Format pelaporan kapal.

Sumber daya manusia merupakan faktor penentu dalam operasional stasiun VTS Tanjung Emas. Jumlah SDM yang dijadikan standar dalam ketentuan IALA V-103 dan Peraturan Menteri Perhubungan nomor 26 tahun 2011 tentang Telekomunikasi Pelayaran adalah sebagai berikut:

1. Manager VTS : 1 orang

2. Teknisi : 2 orang

3. Supervisor : 5 orang

4. Operator : 15 orang

5. Administrasi : 3 orang

Kondisi SDM stasiun VTS

Tanjung Emas saat ini adalah sebagai berikut:

1. Manager VTS : 1 orang;

2. Teknisi : 2 orang;

3. Supervisor : 5 orang;

4. Operator : 15 orang;
5. Administrasi : 3 orang;

6. Tenaga honorer untuk operator: 5 orang;

7. Tenaga honorer untuk administrasi PNBP VTS: 1 orang.

Dari data tersebut, dapat di lihat jumlah SDM yang ada di VTS Tanjung Emas sudah sesuai dengan kualifikasi standar, diharapkan kinerja dari para operator dapat maksimal melakukan tugasnya sebagai operator VTS. Mengingat lalu lintas di laut selalu ada tanpa henti selama 24 jam.

Sejak awal berdirinya VTS di Semarang tahun 2006, telah diadakan beberapa perubahan dan peningkatan perangkat sistem dalam VTS di Semarang yang terdiri dari:
1. Peningkatan
Monitoring

Room Equipment

a. Monitoring room VTS di kantor Distrik Navigasi Kelas II Semarang.

b. Remote site room yang ditempatkan di kantor KSOP Semarang.

2. Peningkatan dan penambahan sensor sistem

a. Sistem redundant peralatan RADAR.

b. Sistem redundant peralatan AIS Transponder.

3. Peningkatan kemampuan peta elektronik

a. Playback software module

b. Chart calibration module

4. VTS Database system

a. VTS database information system;

b. VTS database standalone client terminal;

c. VTS web application;

d. Server computer;

e. Operating system windows server;

f. Akses internet static IP.

5. Infrastruktur renovasi dan perlengkapan interior

a. Renovasi VTS control center di Distrik Navigasi Kelas II Semarang

b. Renovasi remote monitoring 
client di KSOP Semarang

c. Pendirian tower dan pemasangan RADAR GEM setinggi $30 \mathrm{M}$

6. Telephony voice communication with VHF Radio Patching

7. Intelligent Camera System

\section{a. Indoor camera}

b. Outdoor camera

8. CCTV Surveillance (FLIR sensor manager)

VTS Semarang mempunyai peranan strategis dalam rangka menciptakan keamanan, keselamatan pelayaran serta perlindungan lingkungan maritim. Keberadaan stasiun VTS Semarang sangat memberi peran besar bagi para pengguna kapal di pelabuhan, informasi tentang situasi lalu lintas yang ada di laut dan juga informasi tentang bahaya yang ada di sekitar perairan Tanjung Emas dapat diberikan kepada setiap kapal yang melintas. Setiap kapal yang melintas masuk ke daerah VTS Tanjung Emas wajib memanggil VTS melalui radio VHF Ch. 16, lalu kemudian VTS akan menjawab untuk memastikan titik koordinat kapal tersebut sesuai dengan koordinat yang ada di monitor VTS. Tidak hanya itu, informasi terkait jenis muatan kapal, jumlah kru kapal, pelabuhan terakhir yang disinggahi kapal dan bahkan dalam beberapa kondisi VTS juga akan bertanya mengenai kewarganegaraan nahkoda dan para kru kapal. Begitu juga saat kapal yang akan melintas keluar daerah VTS Tanjung Emas, wajib memanggil melalui radio VHF dan melaporkan koordinat kapal serta pelabuhan tujuan berikutnya. Jika kapal yang memanggil VTS tidak mendapatkan jawaban maka alternatif lain adalah dengan memanggil melalui kapal pandu terdekat, pandu yang sedang ada di atas kapal tersebut akan menghubungi kapal pandu dan status yang ada akan disampaikan melalui kapal pandu tersebut ke VTS.

\section{KESIMPULAN}

Dari penelitian ini dapat diambil kesimpulan bahwa dengan adanya VTS Tanjung Emas telah memberikan informasi yang berguna bagi kapal yang melintasi daerah Tanjung Emas, sistem informasi yang dimiliki oleh kantor VTS Semarang juga telah cukup membantu dalam menyampaikan informasiinformasi kepada kapal. Dengan adanya VTS Tanjung Emas telah memberikan sumbangsih pendapatan ekonomi kepada negara dalam bentuk PNBP.

\section{DAFTAR PUSTAKA}

BPS. (2017). Survey Sosial Ekonomi Nasional (SUSENAS) Maret 2017. Badan Pusat Statistik. Jakarta.

Claudet, J., Loiseau, C., Sstres, M., \& Zupan, M. (2020). Underprotected Marine Protected Areas in a Global Biodiversity Hotspot. One Earth, Vol. 2(4), 380-384.

H.B. Sutopo. 1996. Metodologi Penelitian Kualitatif. Surakarta : Universitas Sebelas Maret Press

Martin, R., Tyler, P., Storper, M., Evenhuis, E., \& Glasmeier, A. (2018). Globalization at a critical conjuncture? Cambridge Journal of Regions, Economy and Society, Vol. 11 (1), 3-16.

Michie, J. (2017). Advanced Introduction to Globalisation. Cheltenham: Edward Elgar.

Mohaghegh, A. (2016). Move Toward Economic Globalization with a Scientist. Procedia Economics and Finance, Vol. 36, 467-479.

Moleong, Lexy J. (2014). Metodologi Penelitian Kualitatif. PT. Remaja Rosdakarya. Bandung

Pemerintah Indonesia. (2008). UndangUndang Negara Republik Indonesia Nomor 17 tahun 2008 tentang Pelayaran.

Scott, D. (2019). Indonesia Grapples with the Indo-Pacific: Outreach, Strategic Discourse, and Diplomacy. Journal of Current 
Southeast Asian Affairs, Vol 38(2), 194-217.

Shrestha, N., Shad, M. Y., Ulvi, O., Khan, M. H., KaramehicMuratovic, A., Nguyen, U.-S. D., et al. (2020). The impact of COVID-19 on globalization. One Health, 11: 100180.

Sugiyono. (2014) Metodologi Penelitian Kuantitatif. Kualitatif dan (R\&D). Alfabrta. Bandung.

Thushari, G., \& Senevirathma, J. (2020). Plastic pollution in the marine environment. Heliyon, Vol. 6(8).

Turedi, O., \& Ozer-Caylan, D. (2021). Developing a grounded theory of national maritime policies based on safety, security and environment. Journal of International Maritime Safety, Environmental Affairs, and Shipping, 5:2, 84-97.

Viglione, G. (2021). Fevers are plaguing the oceans - and climate change is making them worse. Nature, 593, 26-28.

Xu, M., Pan, Q., Muscoloni, A., Xia, H., \& Cannistraci, C. V. (2020). Modular gateway-ness connectivity and structural core organization in maritime network science. Nature Communications, Vol. 11(2849). 